\title{
Anticipating IQOS market expansion in the United States
}

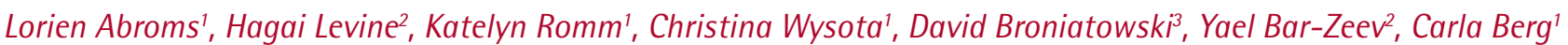

\begin{abstract}
IQOS is sold globally in over 60 countries and entered the US market in 2019 and by 17 May 2021, it was sold in four states: Georgia (Atlanta, Buford), Virginia (Richmond, Tysons), North Carolina (Charlotte, Raleigh), and South Carolina (Charleston, Myrtle Beach), and had 52 specialty stores and 400 retail outlets. While US sales stopped on 29 November 2021 due to a patent lawsuit, they may resume in the near future. As IQOS distribution will likely expand in the future throughout the US, surveillance systems are needed to inform local and national regulatory efforts. Key decision-driving factors for IQOS expansion likely include: 1) general market factors such as larger population/market size and higher median household income; 2) specific IQOS target market factors such as higher consumer spending and smoker prevalence; and 3) more lenient tobacco control context (e.g. cigarette excise taxes, smoke-free policies, state cessation/prevention funding). Likely targets for expansion are markets in Nashville, Tennessee; St. Louis, Missouri; and Louisville, Kentucky. Public health surveillance efforts should monitor IQOS market expansion (e.g. new markets, online direct-toconsumer sales) and IQOS marketing activities (e.g. advertisements, direct marketing, social media, point-of-sale promotions, product trials).
\end{abstract}

\section{COMMENTARY}

IQOS, Philip Morris International's (PMI) heated tobacco product, is currently sold in over 60 countries with over 17 million users and has the largest market share globally among heated tobacco products ${ }^{1,2}$. IQOS (priced at US\$80-130) is marketed as a high-end alternative to cigarettes ${ }^{3}$. The IQOS device is used with HeatSticks, (also known as HEETS in some markets outside the US), which are IQOS specific short cigarettes that are inserted into the IQOS device for heating. Both IQOS and HeatSticks are sold in IQOS specialty stores, mall kiosks (Figure 1), temporary 'pop-up' stores, and non-specialty retail outlets (e.g. pharmacies, grocery stores, and convenience stores $)^{4}$. Services offered in specialty stores and some retail outlets include general sales and returns, customer support, as well as trials of the IQOS device and the HeatSticks ${ }^{4}$. While IQOS marketing targets current smokers ${ }^{1}$, evidence indicates that it is also reaching non-smokers ${ }^{5}$.

In the US, PMI licensed IQOS to Altria for US sales and distribution, and sales began in September 2019 in Atlanta, Georgia, after authorization from the Food and Drug Administration (FDA) ${ }^{6}$. In July 2020, the FDA authorized that IQOS could be marketed as a 'reduced exposure' product (but denied the request to use 'reduced risk' in marketing, a broader health claim $)^{7}$. In the US, awareness and use of IQOS is low but growing (particularly among current smokers, men, and racial/ethnic minorities $)^{8,9}$. As of 17 May 2021, IQOS had expanded beyond Atlanta, GA, to the following additional markets: Buford, Georgia; Richmond and Tysons, Virginia; North Charlotte and Raleigh, North Carolina; and Charleston and Myrtle Beach, South Carolina ${ }^{10}$. At that time, IQOS had 52
AFFILIATION

1 Milken Institute School of Public Health, The George Washington University, Washington, United States

2 Braun School of Public Health and Community Medicine, The

Hebrew University of Jerusalem and Hadassah, Jerusalem, Israel 3 Department of Engineering Management and Systems Engineering,

The George Washington University, Washington, United States

\section{CORRESPONDENCE TO}

Lorien Abroms. Milken Institute School of Public Health, The George Washington University, 950 New Hampshire Avenue, Washington, DC 20052, United States. E-mail: Iorien@gwu.edu ORCID ID: https:// orcid.org/0000-0001-6859-283X

\section{KEYWORDS}

tobacco control, tobacco marketing, alternative tobacco products, heated tobacco products

Received: 29 July 2021

Revised: 7 December 2021

Accepted: 9 December 2021 
specialty stores (including stand-alone stores, kiosks, pop-up stores) and 400 non-specialty retail outlets in the US (see Supplementary file for list of IQOS stores and outlets by market $)^{10}$. The online store was not yet available, although the IQOS website indicated that it was 'coming soon' and same-day delivery was available in some local markets ${ }^{10}$. On 29 November 2021, imports and sales of IQOS were halted in the US when the US International Trade Commission ruled that the IQOS device infringed on the patent rights of a rival tobacco company ${ }^{11}$. PMI has faced similar patent suits in other countries and won (e.g. Greece and UK), and it is expected by industry observers that PMI will sue to overturn the court ruling in the US and resume its US sales in the near future ${ }^{11,12}$. Philip Morris has also indicated its intention to return to US markets. In addition to legal approaches, this could occur by PMI altering the device so that it no longer infringes on disputed patents $^{12}$.

As PMI is likely to expand IQOS distribution in the US following the hiatus related to the patent dispute, as well as continue its global expansion ${ }^{1}$, consideration is currently needed to plan for monitoring of its sales and marketing. Surveillance systems will be needed to inform local and national regulatory efforts and keep pace with expansion efforts. Based on past marketing of tobacco products ${ }^{13}$, factors contributing to expansion decisions are likely influenced by three categories of factors: 1) general market factors such as larger population/market size and higher median household income ${ }^{13,14}$; 2) specific IQOS target market factors such as higher consumer spending and smoker culture and prevalence ${ }^{1,3,14}$; and 3) more lenient tobacco control context (e.g. cigarette excise taxes, smoke-free policies, state cessation/prevention funding $)^{15}$. Table 1 provides an overview of the initial three markets in the US (Atlanta, Richmond, Charlotte) across these dimensions and provides related data regarding other potential markets. Based on these metrics, potential markets include those in states that make up 'Tobacco Nation' (i.e. Alabama, Arkansas, Indiana, Kentucky, Louisiana, Michigan, Mississippi, Missouri, Ohio, Oklahoma, Tennessee, West Virginia), where smoking prevalence is high and tobacco control is lenient ${ }^{14,15}$. Markets within these states are likely to be those with sufficiently large metropolitan areas with at least average or higher than average consumer spending such as Nashville, Tennessee, St. Louis, Missouri and Louisville, Kentucky ${ }^{15}$.

\section{CONCLUSION}

Public health surveillance efforts are needed in the US and globally to monitor the expansion of heated tobacco products such as IQOS (e.g. new markets, online direct-to-consumer sales), marketing activities (e.g. advertisements, direct marketing, point-of-sale promotions, product trials, social media marketing on Facebook and Instagram), and product awareness and use, especially given the disproportionate impact of such products among youth. Surveillance could entail standard methods (e.g. surveys, point-of-sale audits), as well as novel methods including online

Figure 1. IQOS kiosk at Tysons Corner Center in Tysons, Virginia on 22 May 2021, one of 21 IQOS stores within 25 miles of the 2000 zip code

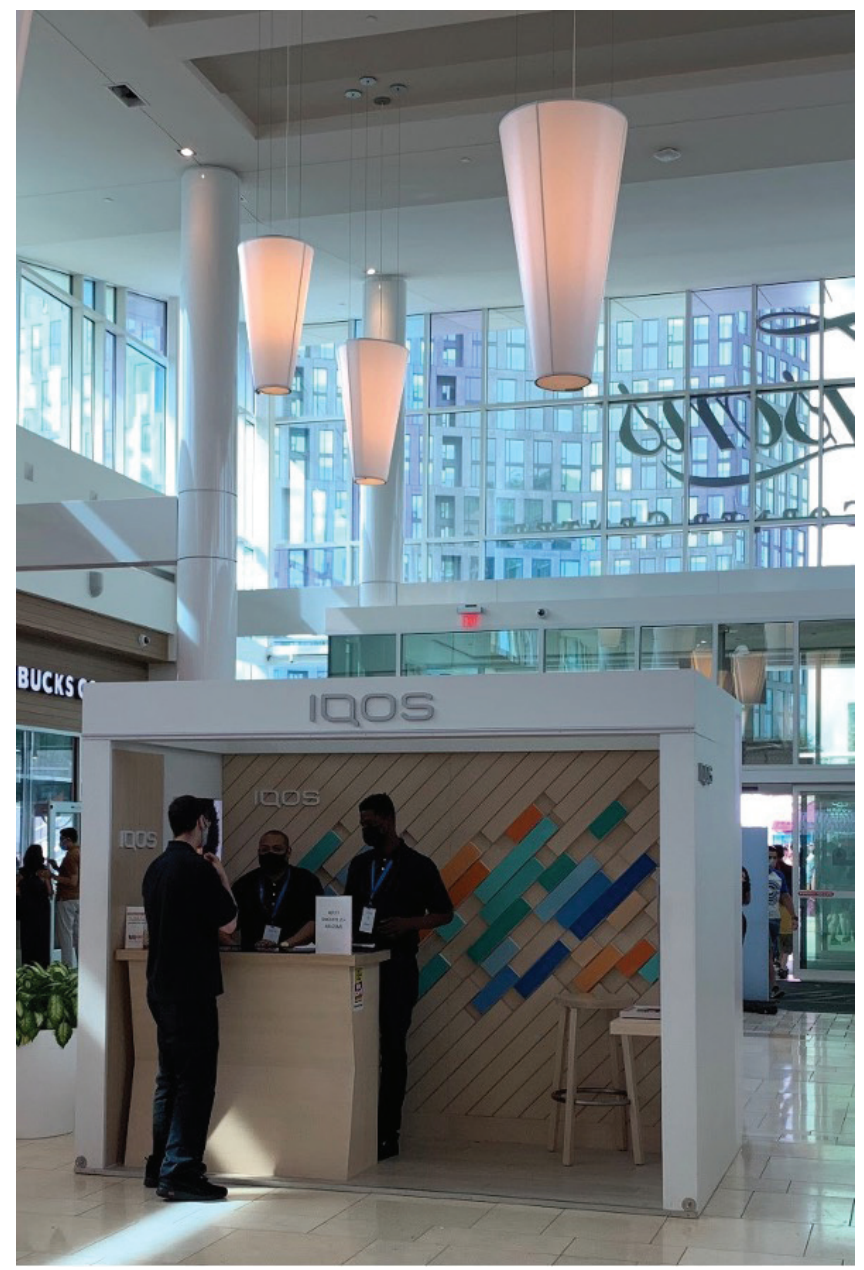


Table 1. Characteristics of initial launch sites and potential markets

\begin{tabular}{|c|c|c|c|c|c|c|c|}
\hline & \multicolumn{2}{|c|}{$\begin{array}{c}\text { Atlanta, GA } \\
\text { (Estimates) }\end{array}$} & \multicolumn{2}{|c|}{$\begin{array}{c}\text { Richmond, VA } \\
\text { (Estimates) }\end{array}$} & \multicolumn{2}{|c|}{$\begin{array}{c}\text { Charlotte, NC } \\
\text { (Estimates) }\end{array}$} & $\begin{array}{c}\text { Other potential markets } \\
\text { Large/medium-sized metro areas in } \\
\text { the following states }\end{array}$ \\
\hline Population $^{\mathrm{a}}$ & \multicolumn{2}{|c|}{5803000} & \multicolumn{2}{|c|}{232866} & \multicolumn{2}{|c|}{2054000} & \\
\hline $\begin{array}{l}\text { Median } \\
\text { household } \\
\text { income }^{\text {b }} \\
\text { (US Median: } \\
\text { \$63179) }\end{array}$ & \multicolumn{2}{|c|}{$\$ 60000$} & \multicolumn{2}{|c|}{$\$ 47000$} & \multicolumn{2}{|c|}{$\$ 53000$} & \\
\hline \multirow{2}{*}{$\begin{array}{l}\text { Total personal } \\
\text { consumption } \\
\text { expenditures } \\
\text { by state (in } \\
\text { millions) }\end{array}$} & \multicolumn{2}{|c|}{$\$ 404263.7$} & \multicolumn{2}{|c|}{$\$ 397230.5$} & \multicolumn{2}{|c|}{$\$ 389094.9$} & California (1st), Texas (2nd), New York \\
\hline & Prevalence & Rank & Prevalence & Rank & Prevalence & Rank & \\
\hline $\begin{array}{l}\text { State adult } \\
\text { smoking } \\
\text { prevalence }^{b}\end{array}$ & $16.3 \%$ & 28th & $14.0 \%$ & 12th & $18.5 \%$ & 38th & $\begin{array}{l}\text { West Virginia (50th), Kentucky(49th), } \\
\text { Louisiana (48th), } \\
\text { Ohio (47th), Mississippi (46th), } \\
\text { Alabama (45th), Arkansas (44th), } \\
\text { Tennessee (43rd), Missouri (42nd), } \\
\text { Indiana (41st) }\end{array}$ \\
\hline \multirow[t]{2}{*}{$\begin{array}{l}\text { State youth } \\
\text { smoking } \\
\text { prevalence }^{b}\end{array}$} & $4.0 \%$ & 7th & $5.5 \%$ & 25 th & $8.3 \%$ & 40th & $\begin{array}{l}\text { Wyoming (51st), West Virginia (50th), } \\
\text { South Dakota (49th), Arkansas (48th), } \\
\text { Minnesota (47th), Oklahoma (46th), } \\
\text { New Mexico (44th), Kentucky (44th), } \\
\text { Louisiana (42nd), Alaska (42nd) }\end{array}$ \\
\hline & $\begin{array}{l}\text { Grade; } \\
\text { Score }\end{array}$ & Rank & $\begin{array}{l}\text { Grade; } \\
\text { Score }\end{array}$ & Rank & $\begin{array}{l}\text { Grade; } \\
\text { Score }\end{array}$ & Rank & \\
\hline 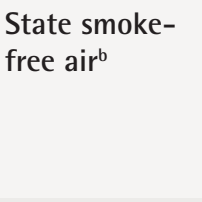 & $C ; 29$ & 40th & $\mathrm{F} ; 18$ & $43 \mathrm{rd}$ & $\mathrm{F} ; 22$ & $41 s t$ & $\begin{array}{l}\text { Kentucky (50th), West Virginia (49th), } \\
\text { Texas (48th), South Carolina (47th), } \\
\text { Mississippi (46th), Alabama (45th), } \\
\text { Missouri (44th), Virginia (43rd), } \\
\text { Alaska (42nd), North Carolina (41st) }\end{array}$ \\
\hline $\begin{array}{l}\text { Prevention } \\
\text { and cessation } \\
\text { funding }^{\mathrm{b}}\end{array}$ & $F ; 3.0 \%$ & 50th & $F ; 12 \%$ & 32nd & F; $5.4 \%$ & 46th & $\begin{array}{l}\text { Georgia (50th), Missouri (50th), Texas } \\
\text { (49th), New Jersey (48th), Michigan } \\
\text { (47th), North Carolina (46th), } \\
\text { Washington (44th), Nevada (45th), } \\
\text { Connecticut (43rd), Alabama (42nd) }\end{array}$ \\
\hline $\begin{array}{l}\text { Cigarette tax } \\
\text { (per pack) }\end{array}$ & $\mathrm{F} ; 13$ & 45th & $\mathrm{F} ; 12$ & 46th & $\mathrm{F} ; 16$ & 37 th & $\begin{array}{l}\text { Alabama (51st), South Carolina } \\
\text { (50th), Nebraska (46th), North Dakota } \\
\text { (46th), Tennessee (46th), Virginia } \\
\text { (46th), Georgia (45th), Kentucky } \\
\text { (44th), Texas (43rd) }\end{array}$ \\
\hline
\end{tabular}

Bold indicates states where IQOS stores and distribution retailers for HEETS exist. a 2020; https://www.bhthechange.org/wp-content/uploads/2018/01/state-of-tobacco-control. pdf. b 2019; https://www.tobaccofreekids.org/assets/factsheets/0176.pdf. c https://apps.bea.gov/iTable/iTable.cfm?reqid=70\&tstep=1\&tacrdn=7\# reqid=70\&tstep=1\&tacrdn=7" https://apps.bea.gov/iTable/iTable.cfm?reqid=70\&tstep $=1$ \&tacrdn=7\# reqid=70\&step=1\&tacrdn=7. Rank refers to number on list from 1 to 51 (all states and DC) with 1 being best and 51 being the worst.

listening tools such as Tobacco Watcher (https:// tobaccowatcher.globaltobaccocontrol.org/), Google Trends, and CrowdTangle for Academics and Researchers for social media monitoring ${ }^{16}$. As online stores are country specific, tools like CyberGhost can be used to visit IQOS online stores globally to understand regional differences in online sales and marketing strategies. These online tools allow 
researchers and practitioners to create interactive dashboards and alerts to understand: 1) public perception of IQOS; 2) marketing impacts in nearreal time and by geographical region; and 3) tobacco company use of global online platforms (e.g. online stores, social media) to circumvent regulatory policy. Such surveillance can help targeted jurisdictions to prepare regulatory action and inform future local, state and federal regulatory efforts in the US, as well as globally.

\section{REFERENCES}

1. Tobacco Business. PMI Talks New IQOS Releases, SmokeFree Future Growth. March 1, 2021. Accessed May 17, 2021. https://tobaccobusiness.com/pmi-talks-new-iqosreleases-smoke-free-future-growth/

2. Philip Morris International. Frequently asked questions about cigarettes and smoking: In how many countries do you sell your cigarette brands? 2020. Accessed May 17, 2021. https://www.pmi.com/faq-section/smoking-andcigarettes

3. Jackler RK, Ramamurthi D, Axelrod A, et al. Global Marketing of IQOS The Philip Morris Campaign to Popularize "Heat Not Burn" Tobacco. SRITA White paper. Stanford University School of Medicine; February 21, 2020. Accessed May 17, 2021. https://tobacco-img. stanford.edu/wp-content/uploads/2021/07/21231822/ IQOS_Paper_2-21-2020F.pdf

4. Churchill V, Weaver SR, Spears CA, et al. IQOS debut in the USA: Philip Morris International's heated tobacco device introduced in Atlanta, Georgia. Tob Control. 2020;29(e1):e152-e154. doi:10.1136/tobaccocontrol-2019-055488

5. Gallus S. Heat-not-burn tobacco products: concerns from the Italian experience. Tob Control. 2019;28(1):113-114. doi:10.1136/tobaccocontrol-2017-054054

6. US Food and Drug Administration. FDA permits sale of IQOS Tobacco Heating System through premarket tobacco product application pathway. Food and Drug Administration. April 30, 2019. Accessed May 21, 2021. https://www.fda.gov/news-events/pressannouncements/fda-permits-sale-iqos-tobacco-heatingsystem-through-premarket-tobacco-product-applicationpathway

7. US Food and Drug Administration. FDA Authorizes Marketing of IQOS Tobacco Heating System with 'Reduced Exposure' Information. July 7, 2020. Accessed January 21, 2022. https://www.fda.gov/news-events/ press-announcements/fda-authorizes-marketing-iqostobacco-heating-system-reduced-exposure-information

8. Czoli CD, White CM, Reid JL, O'Connor RJ, Hammond D. Awareness and interest in IQOS heated tobacco products among youth in Canada, England and the USA. Tob Control. 2020;29(1):89-95. doi:10.1136/tobaccocontrol-2018-054654

9. Berg CJ, Romm KF, Patterson B, Wysota CN. Heated tobacco product awareness, use, and perceptions in a sample of young adults in the U.S. Nicotine Tob Res. 2021. Nicotine Tob Res. 2021;23(11):1967-1971. doi: $10.1093 / \mathrm{ntr} / \mathrm{ntab} 058$

10. IQOS. Accessed May 17, 2021. https://www.getiqos.com/ pages/home/where-to-find-iqos/store-locator.html.

11. Lucas A. Philip Morris, Altria banned from importing or selling Iqos tobacco device in the U.S. CNBC. September 30, 2021. Accessed October 21, 2021. https://www.cnbc. com/2021/09/30/philip-morris-altria-banned-fromselling-iqos-tobacco-device-in-the-us.html.

12. Lucas A. Altria can't sell Iqos in the U.S. as Biden administration opts to not intervene in patent dispute. CNBC. November 30, 2021. Accessed December 1, 2021. https://www.cnbc.com/2021/11/30/altria-cant-sell-iqosin-us-as-biden-wont-intervene-in-patent-dispute.html

13. Mariadoss, BJ. Using Demographics to Guide Global Marketing Strategy. Core Principles of International Marketing. 2019. Accessed May 17, 2021. https:// opentext.wsu.edu/cpim/chapter/6-6-usingdemographics-to-guide-global-marketing-strategy/

14. US Bureau of Economic Analysis. Personal consumption expenditures by state, 2019. October 8, 2020. Accessed May 21, 2021. https://www.bea.gov/news/2020/ personal-consumption-expenditures-state-2019

15. Truth Initiative. Tobacco Nation: an ongoing crisis. June 6, 2019. Accessed May 21, 2021. https://truthinitiative. org/tobacconation

16. Freeman B. New media and tobacco control. Tob Control. 2012;21(2):139-144. doi:10.1136/tobaccocontrol-2011-050193

\section{CONFLICTS OF INTEREST}

The authors have completed and submitted the ICMJE Form for Disclosure of Potential Conflicts of Interest and none was reported.

\section{FUNDING}

This research was partly funded by the National Cancer Institute (US $\mathrm{NCl}:$ R01CA239178-01A1)

\section{ETHICAL APPROVAL AND INFORMED CONSENT}

Ethical approval and informed consent were not required for this study.

\section{DATA AVAILABILITY}

The data supporting this research are available from the authors on reasonable request.

PROVENANCE AND PEER REVIEW

Not commissioned; externally peer reviewed. 